\title{
Experiencias de la enseñanza en época de pandemia: la respuesta de los estudiantes
}

Laura Consuelo Flores González

\section{Resumen}

En un inicio, la noticia sobre la pandemia generó entre los alumnos felicidad porque no tendrían que ir a la escuela, pero con el paso de los meses esa felicidad cambio por ansiedad y por un anhelo por regresar a un salón de clases.

Palabras clave: pandemia, enseñanza, aprendizaje, regreso a clases, experiencia.

\section{TEACHING EXPERIENCES IN TIMES OF PANDEMIC: THE STUDENTS' RESPONSE}

\begin{abstract}
At first, the news about the pandemic generated happiness among the students, because they would not have to go to school, but as the months went by, that happiness changed due to anxiety and a desire to return to a classroom.
\end{abstract}

Keywords: pandemic, teaching, learning, return to school, experience. 


\section{Laura Consuelo Flores González}

Lcc.lauraflores@hotmail.com

orcid.org/0000-0001-8944-0202

Licenciada en Ciencias de la Comunicación, con maestría en educación por la Universidad TecMilenio. Formadora de instructores de alto impacto por el Instituto Tecnológico de Monterrey, docente certificada en educación media superior por ANIUES, actualmente coordinadora académica de BGCCentro Universitario UTEG.

Cuenta con 12 años de experiencia como docente, apasionada por la educación e investigadora independiente de la enseñanza y la transformación del idioma español. su salón y que ya no estarían con sus profesores mientras explicaban la lección del día.

Fue fatídico. 16 de marzo, "estamos en cuarentena", dicen las autoridades. Todo se paralizó por los altos contagios del coronavirus y las noticias sobre lo que pasaba en China y en España estaban a la orden del día.

Mis alumnos me preguntaban por correo y por redes sociales que si era verdad que no tendríamos clases y mi respuesta siempre fue la misma "por el momento NO y NO salgan de sus casas". Esa respuesta les causaba una felicidad impresionante: "¡No tendremos clases!", pensaban ellos, "iqué divertido!" Bueno, no era tan divertido porque no podían salir debido a que todo lo que no fuera esencial estaba cerrado. "Pero qué importa, ino tendremos clases, qué chingón!", era lo que leía en las publicaciones de mis alumnos. 
Mientras, las escuelas y los docentes no tardamos en enfrentarnos al gran reto: ilas clases en línea! y por Google Classroom... No miento, fue cansado preparar el material, adecuar las planeaciones, hacer las aulas virtuales para cada materia y lograr avisarles a todos los alumnos que ya tendrían clases en línea. Pero aun así nadie se imaginaba todo lo que viviríamos...

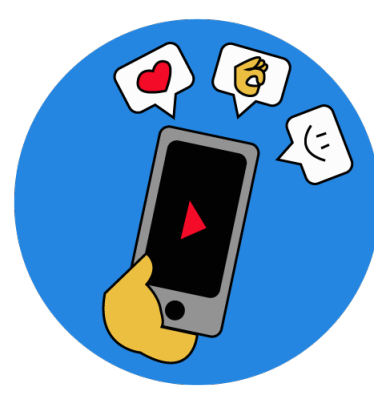

Empezaron las videollamadas por Zoom y con ello otro conflicto, permitir a los alumnos entrar a la intimidad del hogar del docente y viceversa. Allí fue donde las diferencias y las carencias se hicieron notables. No todos los alumnos tienen una computadora o un smartphone con conexión a internet, no todos viven la pandemia de la misma forma. Pasaron las semanas y los meses y cada día los alumnos estaban más estresados por tantas tareas que entregar -y los profesores por tantas tareas que revisar-.

Y aquí es donde los mensajes de mis alumnos cambiaron: "¿Maestra, cuando regresamos a la escuela? Es que en mi casa tengo hermanos que también tienen que hacer y entregar tareas y sólo tenemos una computadora en casa", "¿Cuándo regresamos?", "iMaestra, ya la extraño!", "¿Maestra, cuando regresamos a la escuela?" Y mi respuesta siempre es la misma: no lo sé.

\section{Cómo citar este artículo}

* Flores González, Laura Consuelo. (2021, enero-febrero). Experiencias de la enseñanza en época de pandemia: la respuesta de los estudiantes. Revista Digital Universitaria (RDU), 22(1). Dol: http://doi.org/10.22201/ cuaieed.16076079e.2021.22.1.7 